\title{
Mobilya endüstrisinde kullanılan kapak konstrüksiyonları üzerine incelemeler
}

\author{
Mehmet Dağlı ${ }^{1}(\mathbb{D})$, Tuncer Dilik $2^{*}$ (D), Ahmet Kurtoğlu ${ }^{3}$ (D)
}

$\ddot{\mathbf{O} z}$

Son yıllardaki mobilya tasarımlarında, işletmelerin sadece kapak konstrüksiyonlarındaki değişiklikler ile yeni modeller oluşturarak mobilya pazarında yer almaya çalıştıkları görülmektedir. $\mathrm{Bu}$ kapsamda, özellikle mutfak mobilyasında kullanılan kapak türleri değerlendirilmiştir. Çok çeşitli ürün yelpazesi olan mobilya endüstrisinde, özellikle mutfak, banyo, ofis, TV üniteleri gibi modül standartlarının bulunduğu alanlarda, kapaklar kuşkusuz modülün en önemli parçasını oluşturmaktadır. Kapak, bir modülün ilk göze çarpan ve gövde bölümünü oluşturan diğer parçalara göre, daha fazla işçilik ve özenli bir çalışma gerektiren kısmıdır. Bu nedenle, kapakların üretim safhaları büyük önem kazanmaktadır. Araştırmada, kapak konstrüksiyonlarının çeşidini kapağın hareket biçiminin belirlediği ve kullanım yerlerine göre birleştirme yöntemlerinin uygulanmasının gerekliliği ortaya çıkmıştır. Bunun yanında, kapakların üretim maliyeti üzerindeki paylarının, seçilen kapak modellerine göre değiştiği de görülmekte olup, üretim maliyetinde en fazla paya sahip olan kapakların lake uygulamalı modeller olduğu belirlenmiştir. Sonuç olarak, mobilya üreticilerinin gerek uluslararası rekabet gerekse model geliştirilmesindeki etkinliğin arttırılması açısından kapak konstrüksiyonlarına yönelik Ar-Ge ve Ür-Ge çalışmalarına öncelik vermelerinin önemi vurgulanmış ve önerilmiştir.

Anahtar kelimeler: Mobilya kapakları, mutfak mobilyası, lake kapak, membran kapak

\section{Examinations on cover constructions used in furniture industry}

\begin{abstract}
In recent years, in furniture designs, it is seen that enterprises try to take part in the furniture market by creating new models only with the changes in the cover constructions. Therefore, the cover constructions in wooden furniture were examined. In the furniture industry where module standards exist, cover constructions are undoubtedly the most important part of the module. The cover is the first eye-catching part of the module that requires more and careful work than the other parts of the body. So, the production stages of the cover constructions are of great importance. In the research, it is revealed that the type of the cover is determined by the movement patterns of the cover and it is necessary to apply the joining methods according to the place of use. Furthermore, it can be covers have a significant share in furniture costs. In addition, it is determined that the covers having the highest share in the production cost are the lacquered application models. As a result, in the framework of the findings, it was emphasized and suggested the importance of furniture manufacturers to prioritize $R \& D$ studies for cover constructions in terms of increasing international competitiveness and efficiency in model development.
\end{abstract}

Keywords: Furniture covers, kitchen furniture, lacquered cover, membran cover 


\section{Giriş}

Kapaklar, bilindiği gibi mobilyaların önünü kapatan, gerektiğinde açılıp kapanabilen, herhangi bir eşyanın gizlenip görünmemesini sağlayan mobilya elemanları olarak tanımlanmaktadır. Tanımından da anlaşılacağı gibi mobilyaların işlevsel özellikleri üzerinde kapaklar, mobilyanın içerisine konan eşyaları dış etkilerden koruma, kilit, sürgü vb. kapatma mekanizmaları takılmak suretiyle önemli evrak, doküman, malzeme ve eşyaların saklanmasına yardımcı olma gibi önemli görevler üstlenmektedir. Günümüzde, kullanım yeri ve amacina göre değişmekle birlikte mobilyalarda masif ahşap, lif levha, yonga levha, kontrplak vb. ahşap malzemelerden yapılmış kapakların yanı sıra metal alaşımlar, plastikler ve camlardan yapılmış kapakların kullanılmakta olduğu görülmektedir. Örneğin, cam kapaklar daha çok ecza dolabı, vitrin, ilan dolabı ve benzeri teşhir amaçlı kullanılan mobilyalarda kullanılmaktadır (Dilik, 2019; Dilik ve Uçar, 2017).

Literatür bilgilerine göre kapakların farklı gruplar altında sınıflandırıldıkları görülmektedir. Ancak, genellikle tanımlamalarda kapakların açılıp kapanma özelliklerine göre sınıflandırıldığı anlaşılmaktadır. Bu kapsamda, bir kapağın çalışma şekli, kapak hangi konstrüksiyon tekniği ile yapılmışsa o yapım tekniğinin ismiyle tanımlanmakta olduğu görülmektedir. Kapağın konstrüksiyonu ve açılma şeklinin ise, mobilyanın kullanılacağı yere, teknolojik şartlara, duyulan gereksinmeye ve müşterinin isteğine bağlı olduğu belirtilmektedir (Dilik ve Uçar, 2017; Kurtoğlu ve Dilik, 2019; 2020; Kurtoğlu, 2000).

Son yıllardaki mobilya tasarımlarında, işletmelerin sadece kapak konstrüksiyonlarındaki değişiklikler ile yeni modelleri oluşturarak mobilya pazarında yer almaya çalıştıkları görülmektedir. $\mathrm{Bu}$ amaçla, ahşap mobilyalarda kapak konstrüksiyonlarının incelenmesi konulu bu araştırmada, mobilya üretimindeki kapak konstrüksiyonlarının gelişimi ortaya konulmaya çalışılarak mobilya sektöründeki tercih durumlarının belirlenmesi ve üretim maliyetlerinin karşılaştırılması hedeflenmiştir.

\section{Metot}

Bu çalışmada, literatür incelenmesi, gözlem ve analize dayanan bir yöntem izlenmiştir. $\mathrm{Bu}$ kapsamda, sipariş tipi üretim yapan bir işletmedeki, özellikle mutfak mobilyasında kullanılan kapak türleri esas alınarak;

1- Kapak konstrüksiyonlarının tasarım ve model geliştirmedeki etkisinin mobilya sektörü açısından öneminin ortaya konulması,

2- Mutfak trendlerinin etkisi de gözetilerek mutfak mobilyasında en çok tercih edilen kapak türlerinin belirlenmesi,

3- Gerek üretici, gerekse tüketici tercihinin belirlenmesinde etkili olan birim maliyetlerinin kapak türlerine göre seçilen örnek projeler üzerinden karşılaştırmalarının yapilmas1,

4-Gerek uluslararası rekabet gerekse sektörel gelişme açısından kapak konstrüksiyonlarının Ar-Ge ve Ür-Ge çalışmalarında ki öneminin ortaya konulmasına yönelik bilgi ve bulguların elde edilmesi hedeflenmiştir. 


\section{Bulgular ve Tartışma}

\subsection{Mobilya kapak konstrüksiyonları ile ilgili genel bilgiler}

Kapaklar, mobilyaların ön, yan veya üst açıklıklarını kapatmaya yarayan ve gerektiğinde açılabilen elemanları olarak tanımlanmaktadır (Dilik, 2019). Genel olarak mobilyaların cinsine göre tek veya çok kapaklı olabilirler. Her bir kapak bir mobilya bölmesini kapatıyorsa bunun tek kapaklı bir mobilyanın durumundan farkı yoktur. Fakat çoğu zaman bir mobilya ünitesini iki kapak kapatır. Bu durumda kapağın biri sağa, diğeri sola açılır ve ortada birbiri ile birleşmektedirler (Şekil 1) (Kurtoğlu ve Dilik, 2019; 2020).
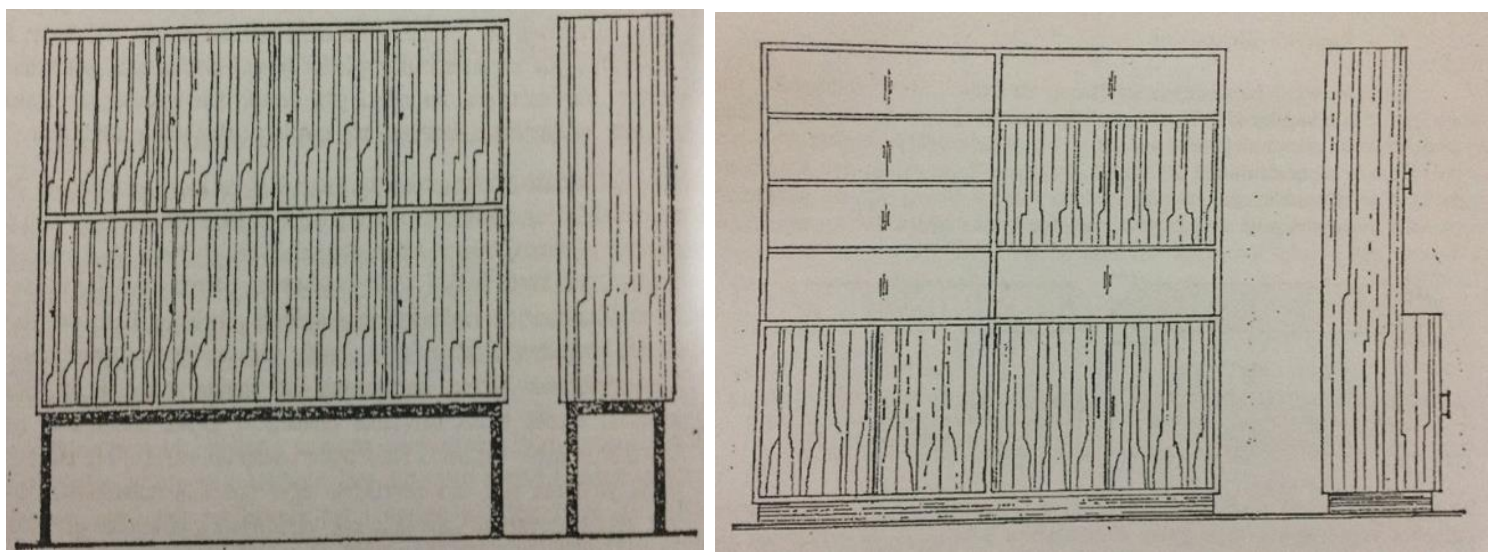

Şekil 1. Bağımsız bölmeli ve çok kapaklı veya çift kapaklı bir mobilya örneği.

Araştırmada en çok kullanılan ortada birleştirme yöntemlerinin; bindirme çıtalı birleştirme şeklinde olduğu ve bunlarında mobilyanın cinsine, stiline, kapakların büyük veya küçük oluşuna ve kullanıldığı yere göre değiştiği ve farklı şekillerde uygulandığ belirlenmiştir (Şekil 2a). Çerçeve konstrüksiyonlu mobilya kapaklarının genellikle ortadan lambalı birleştirilme şeklinde uygulandığı (Şekil 2b), gömme dolaplar ve elbise dolapları gibi yüksek kapaklarda ise, kinişli birleştirmenin tercih edildiği görülmektedir (Şekil 2c). Son zamanlarda, çok kapaklı mutfak dolapları ile kitaplık ve vitrin gibi mobilya kapakların da ise bağımsız açılan kapakların (Şekil 2d) daha çok tercih edilerek uygulama alanını genişletmeye başladığı ortaya çıkmıştır.
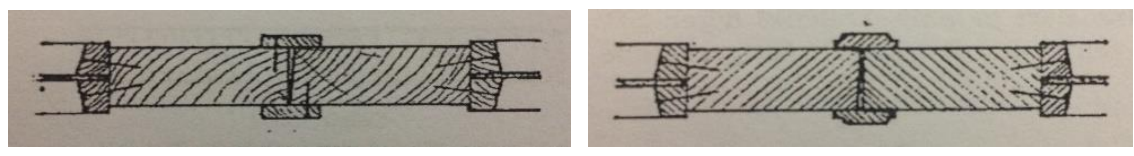

a. Kapaklarda bindirme çıtalı birleştirme örnekleri.
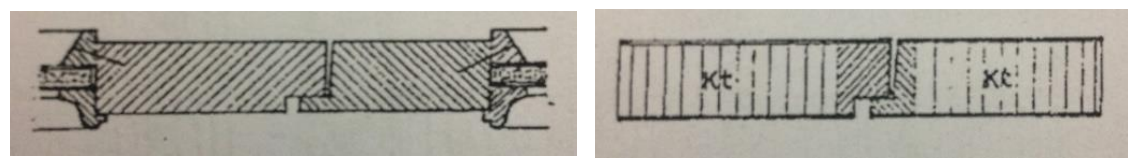

b. Kapaklarda lambalı birleştirme örnekleri.

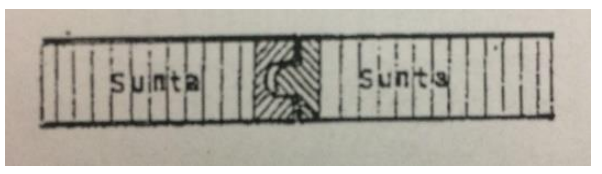

c. Kapaklarda kinişli birleştirme örnekleri 

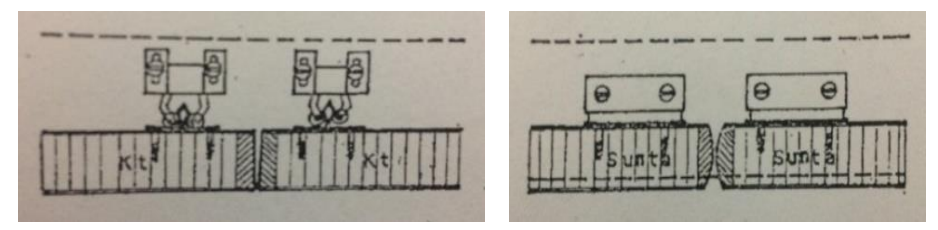

d. Ortada düz ve kavisli birleşen bağımsız kapak örnekleri

Şekil 2. Kapaklarda uygulanan ortada birleştirme yöntemleri (Dilik, 2019)

\subsection{Kapak çeşitleri}

Kapakların genellikle açılıp kapanmalarına göre farklı şekillerde tanımlandığı görülmektedir. Ancak, bir kapak hangi teknikle yapılmış ise o yapım tekniğinin ismiyle anılmaktadır. Buna göre, kapakların; dönerek açılan kapaklar, katlanır kapaklar, sürme kapaklar, düşme kapaklar ve stor kapaklar olarak 5 grup altında sinıflandırılmakta olduğu belirlenmiştir (Dilik, 2019; Kurtoğlu ve Dilik, 2019; Kurtoğlu ve Dilik, 2020).

\subsubsection{Dönerek açlan kapaklar}

Mobilyalarda en çok uygulanan kapak çeşidi olarak bu kapaklar, menteşe mili etrafında kapak genişliği kadar bir yay çizerek açılmaktadır. Dönerek açılan kapakların tek kanat veya çift kanat olmak üzere iki şekilde yapılmakta oldukları görülmektedir. Bu kapak çeşidinin; takılacakları mobilyanın yan tablalarının cumbalarına göre; İçerlek, dişarlak, yüzbeyüz ve bindirme kapak olarak 4 farklı şekilde tasarlandıkları bilinmektedir (URL 1, 2011). Bununla birlikte, uygulamada en çok kullanılan kapak çeşidi olduğu ve bunlarında tüketicinin isteğine göre değişen; içerlek, dişarlak, yüzbeyüz ve bindirme kapak şeklinde tasarlanarak, birbirlerine göre farklı özellikler taşımakta oldukları görülmektedir.

\section{A- İçerlek kapaklar}

İçerlek kapakların yan, alt ve üst tablaların ön cumbalarından 3-5 mm içerlek olacak şekilde takılan bir konstrüksiyona sahip olduklar1 görülmektedir (Şekil 3), (URL 1, 2011). Bu tür kapaklardaki çok hafif sarkmalar, kapağın alt tablaya girdiği yüzeyde vernik, boya veya kaplama sıyrılması gibi yüzeyde deformasyon riski nedeniyle hassasiyet gerektiren bir özellik taşımaktadırlar.

\section{B- Dışarlak kapaklar}

Dışarlak kapaklar, yan, alt ve üst tablaların ön cumbalarından 3-5 mm taşkın olacak şekilde takılan bir konstrüksiyona sahiptirler (Şekil 4), (URL 1, 2011). Bu kapakların zamanla kapağın sarkmasından dolayı alt ve yan tablalarda oluşan tahribatlar, kapak kapalı durumdayken görünmediği için içerlek kapaklara göre daha fazla tercih edilmekte olduğu görülmektedir.

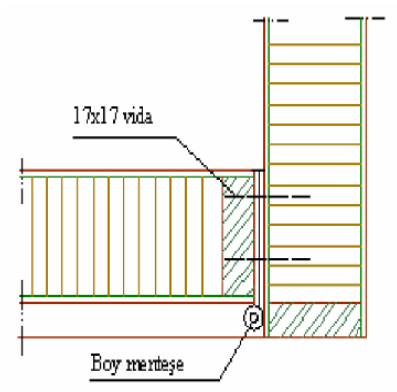

Şekil 3. İçerlek kapak örneği

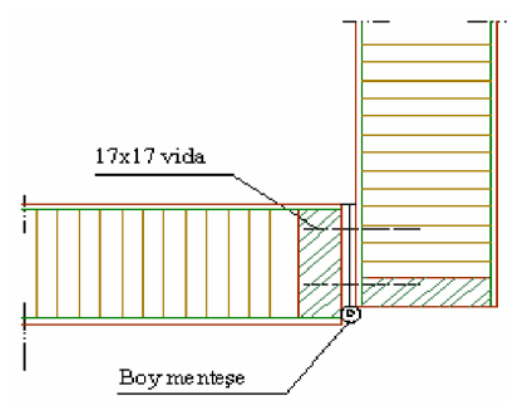

Şekil 4. Dışarlak kapak örneği.

\section{C- Yüzbeyüz kapaklar}


Yüzbeyüz kapaklar; yan, alt ve üst tablaların ön cumbaları ile aynı seviyede takılmış bir konstrüksiyona sahip olan kapaklara denir (Şekil 5), (URL 1, 2011). Bu tür kapakların kaliteli ve hassas yapılması gereken işlerde uygulanmasının fazla tercih edilmediği görülmektedir. Çünkü, mobilya ünitesinin kapak takılacak cumbalarında oluşabilecek küçük bir peşlenme (gönye bozukluğu) veya çarpıklık hemen göze çarpmaktadır.

\section{D- Üstten bindirme kapaklar}

Üstten bindirme kapaklar; mobilyanın yan, alt ve üst tablalarının ön cumbalarını tamamen kapatacak şekilde bir konstrüksiyona sahip olan kapaklara denir (Şekil 6), (URL 1, 2011). Son zamanlarda, en fazla uygulanan kapak çeşitlerinden olduğu görülmektedir. Çünkü bu tür kapaklar da diğer kapak çeşitlerinde belirtilen hatalar ve riskler görülmediği gibi daha kolay ve kısa bir işçilik süresi gerektirmektedir.

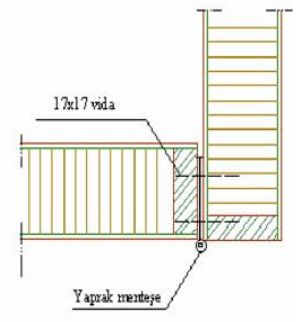

Şekil 5. Yüzbeyüz kapak örneği.
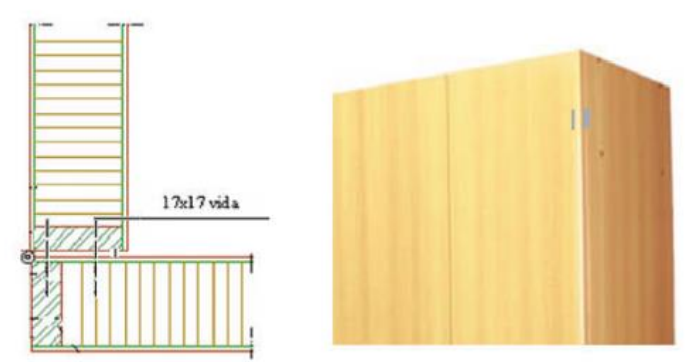

Şekil 6. Üstten bindirme kapak örneği.

\subsubsection{Katlanır kapaklar}

Katlanır kapaklar, en az iki ayrı kapağın menteşe vb. bağlantı mekanizması kullanılarak birbirine eklenmesi sonucu elde edilen kapaklara denir (Şekil 7), (URL 1, 2011). Burada menteşe kullanmaktaki amaç, kapakların sağa veya sola açılırken katlanmasını sağlamaktır. Katlanır kapakların çalışma sistemi, dönerek açılan kapakların ve sürme kapakların çalışma sistemine benzemektedir.

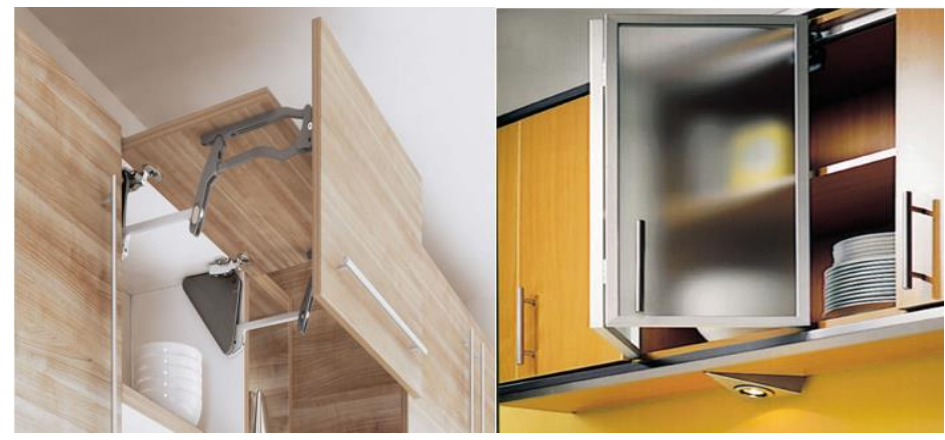

Şekil 7. Katlanır kapak örneği.

\subsubsection{Sürme kapaklar}

Sürme kapaklar, bir kiniş-kanal içerisinde veya ray üzerinde hareket eden ve mobilya dışına taşmadan açılıp kapanmayı sağlayan bir konstrüksiyona sahip olan kapaklardır (Şekil 8), (URL 1, 2011). Mobilyanın yan tablalarına paralel olarak, itme ve çekmeye dayanan bir çalışma sistemine sahiptirler. 


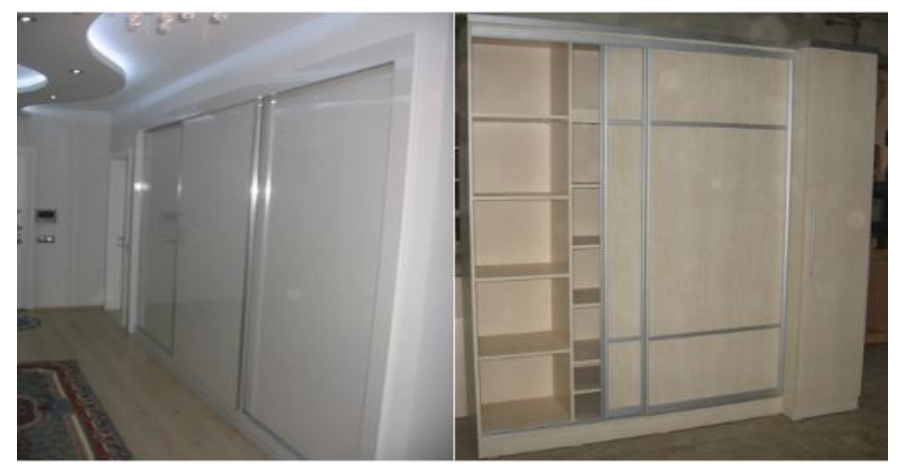

Şekil 8. Sürme kapak örneği.

\subsubsection{Düşme kapaklar (kalkar kapaklar)}

$\mathrm{Bu}$ kapakları, yukarıdan aşağıya veya aşağıdan yukarıya doğru dönerek açılan ve açıldığı zaman yatay duruma gelmeyi sağlayan bir konstrüksiyona sahip kapaklar olarak tanımlayabiliriz (Şekil 9), (URL 1, 2011). Bu kapakların daha çok vitrin, büfe, kitaplık vb. gibi sistem mobilyalarda tercih edildikleri ve kullanıldıkları görülmektedir. Diğer kapak çeşitlerine göre, açık durumda iken kullanılabilme gibi farklı özelliklere sahip olmasıdır.
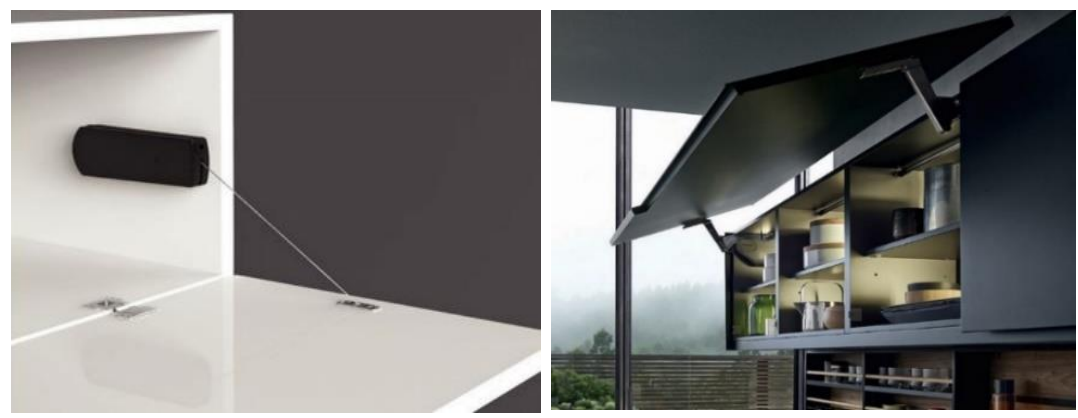

Şekil 9. Düşme kapak örneği.

\subsubsection{Stor kapaklar}

Storlardan yapılmış bir konstrüksiyona sahip kapaklar olarak tanımlanan bu kapaklar, sürme kapaklar gibi açılırken mobilyanın dışına çıkmadan açılan ve kendileri için yapıllmış kinişler içerisinde geriye doğru giderek ya da stor yuvası içinde üst üste sarılarak mobilyanın önünün açılmasını sağlarlar (Şekil 10), (URL 1, 2011). Stor sistemini oluşturan çıtaların, masif, kaplamalı ahşap, metal veya plastik malzemeden yapılabildikleri görülmektedir. $\mathrm{Bu}$ kapaklar, diğer kapak çeşitlerinden farklı olarak aşağıdan yukarıya, yukarıdan aşağı ya da sağa sola doğru açılabilmektedirler.

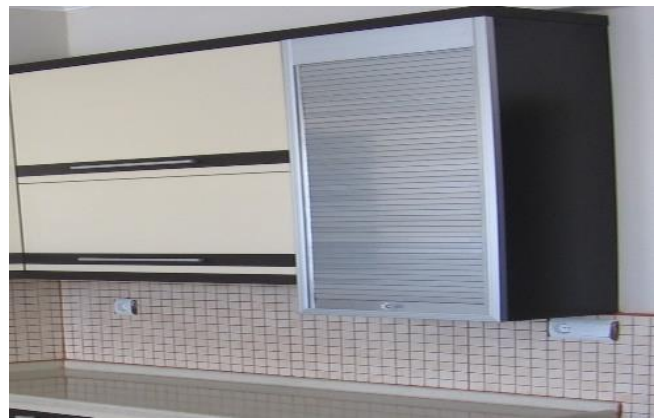

Şekil 10. Stor kapak örneği. 


\subsection{Kapak üretim sistemleri}

Araştırmada, kapak üretim sistemleri, üretimde kullanılan üst yüzey işlemleri ve malzeme türüne göre sınıflandırılarak açıklanmaya çalışılmıştır. Bu kapsamda, kapak üretim sistemleri; akrilik kapaklar, lake kapaklar, metal (alüminyum) kapaklar, membran kapaklar ve cam kapaklar olarak 5 grupta sınıflandırılmış ve açıklanmıştır (Kurtoğlu, 2000; Muğla, 2010; URL 1, 2011; URL 2, 2019; URL 3, 2018; URL 4, 2018; URL 5, 2018; URL 6, 2018; URL 7, 2019).

\subsubsection{Akrilik kapaklar}

Yüksek parlaklığa ve çizilmeye karşı yüksek dirence sahip özelliği ile kullanım tercihini giderek arttırdığ 1 görülmektedir. Genellikle modüler mutfak ve banyo kabinlerinin kapaklarında kullanılmakla birlikte, günümüzde sektörün hemen tüm alanlarında kullanılır hale gelmiştir. Membran ve lake gibi gerek mobilyacıların gerekse mimarların çok yoğun olarak kullandıkları trend ürünlerde de yerini almıştır (URL 1, 2011; URL 2, 2019).

Üretim sistemi basit olup, kullanım alanına göre istenilen ölçülerde ebatlama makineleri ile kesilen akrilik panellerden herhangi bir işleme tabi tutulmaksızın kenar bantlama makineleri ile bantlanarak doğrudan kullanıma uygun hale getirilmiş olurlar. Çok zengin bir renk skalasına sahip olan akrilik kapakların kenarları farklı ya da aynı renkli kenar bantlarıyla kaplanabilmektedir. Ayna yansıması efekti ve \%100 pürüzsüz yüzeyi ile membran kapaklardan çok daha iyi sonuçlar alınabilmektedir. Pürüzsüz yüzey yapısı sayesinde son derece hijyenik bir yapıya sahiptir (Şekil 11).

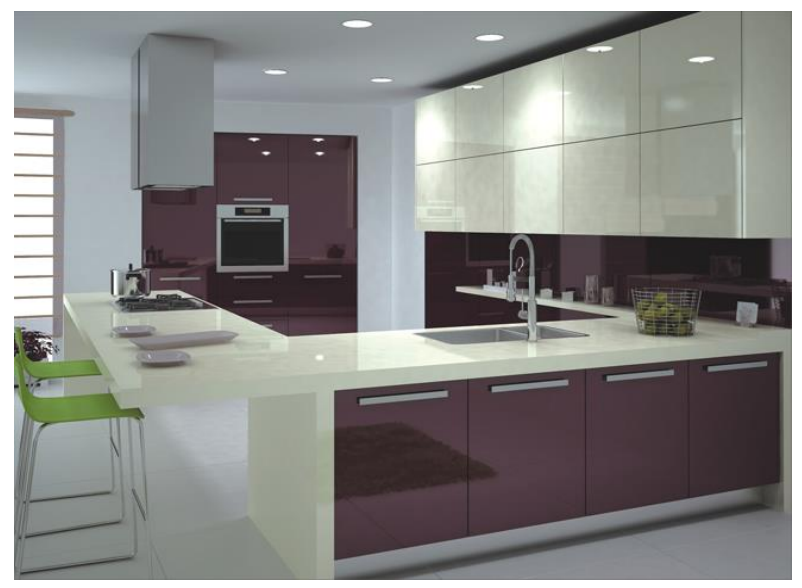

Şekil 11. Akrilik kapak örneği.

\subsubsection{Lake kapaklar}

Genellikle ham MDF vb. levha üzerine astarlama yapıldıktan sonra poliüretan veya akrilik sistem boyaların uygulanması usulüyle yapılan kapaklara lake kapak denir (Şekil 12). Ahşap esaslı levhaların renkli ve örtücü bir gereçle örtülmesi işlemi olan lake boyama işlemi ile doğal yapısı görünmeyen levhalar hem bozucu etkilerden korunmuş hem de istenilen, bir renge boyanmış olurlar. Lake boya denilen bu teknik, mobilya ve iç mimaride sağladığ ekonomik ve teknik yararlar sayesinde kullanımı oldukça yaygınlaşmıştır. Ancak, çok hassas bir çalışmayı ve çok katmanlı bir astarlamayla birlikte ustalık gerektiren bir işlemdir. Arzulanan renklerde mobilya üretme olanağı verir. Renk tercihi yönünden sonsuz tercih olanağı sağlanırken, parlak veya mat görüntülü mobilya üretimine de olanak sağlar (Kurtoğlu, 2000; URL 3, 2018). 


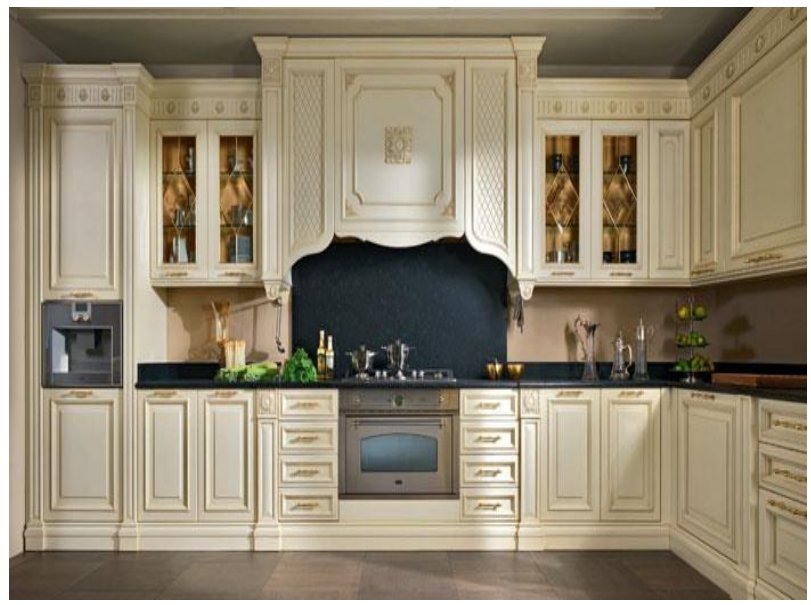

Şekil 12. Lake kapak örneği.

\subsubsection{Metal çerçeve (alüminyum) kapaklar}

Metal çerçeve kapaklar, alüminyum profillerin belirlenen ölçülerde kesilmesi, birleştirilerek çerçeve sekline getirilmesi ve orta kısmına istenilen renk ve modelde camın takılması ile elde edilen bir kapak modelidir (Şekil 13). Kullanım alanı bakımından özellikle mutfak mobilyasında tercih edilebileceği gibi banyo, TV üniteleri vb. gibi birçok alanda da tercih edilmekte olduğu görülmektedir (URL 4, 2018).

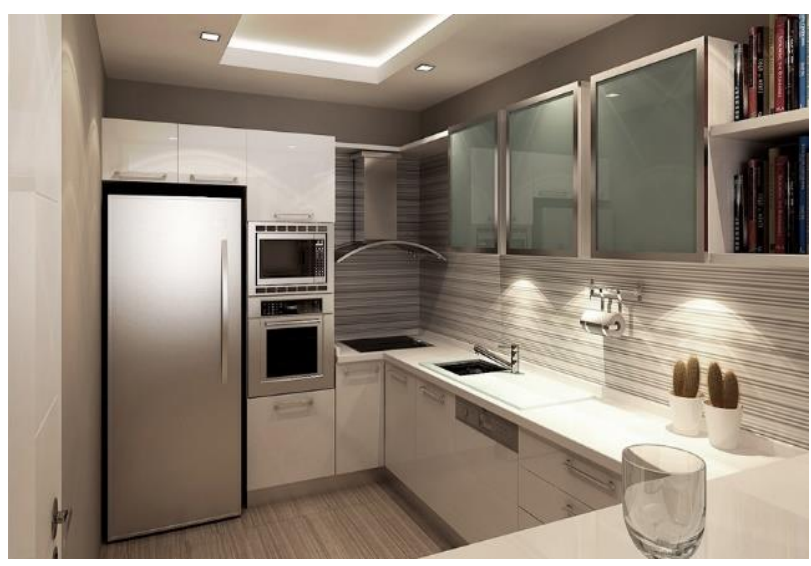

Şekil 13. Metal çerçeve kapak örneği.

\subsubsection{Membran kapaklar}

Membran kapaklar, genellikle tek yüz olarak MDF vb. levha yüzeyine PVC folyonun tek taraflı preslenmesi ile üretilen kapaklar olarak tanımlanmaktadır (Şekil 14). Bu kapaklar, uzun ömürlü olması ve dayanıklılığı ile kullanıcıların tercihlerinde ilk sıralarda yer almaktadır. Çok çeşitli renk ve desen seçenekleri ile mimari ve dekorasyon çözümlerinde aranan bir kapak konstrüksiyonu konumunda olduğu görülmektedir. Üretim tekniği sayesinde komple mono blok olacak şekilde tek parça olarak preslendiği için kapak kenarlarında bantlama işlemi gerektirmemesi, ayrıca renk ve desen bütünlügünü sağlayan bir özelliğe sahip olması kullanım tercihinde bu kapakları ön plana çıkarmaktadır (URL 6, 2018). 


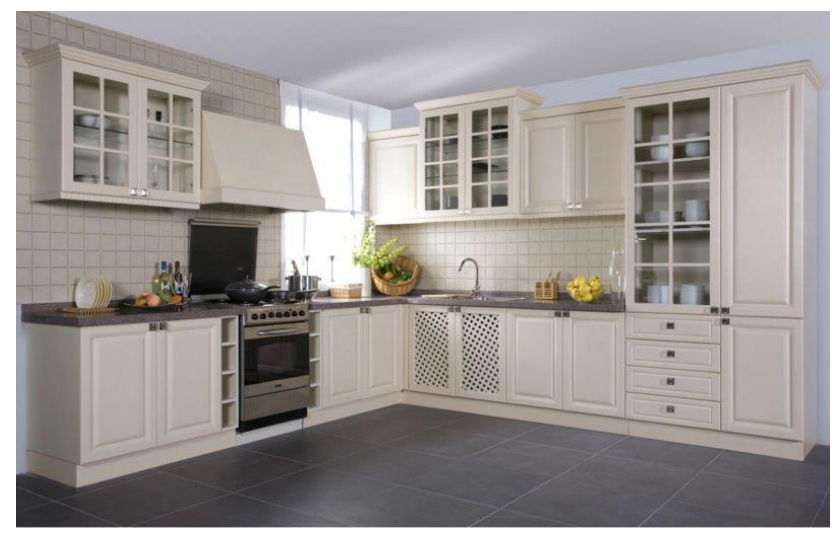

Şekil 14. Membran kapak örneği.

\subsubsection{Cam kapaklar}

Cam işleme teknolojisindeki gelişmeye paralel olarak cam kapakların mobilya endüstrisindeki kullanımı giderek artmaktadır. Mobilya endüstrisinde kullanılan kapak konstrüksiyonlarında dönerek açılan kapaklar, sürme kapaklar, katlamalı kapaklar, düşme kapaklar vb. gibi kullanılan bütün konstrüksiyon tipleri cam kapaklar olarak da üretilmektedir.

İster mevcut bir mutfak yeniden tasarlansın ister yeni bir mutfak kurulsun, cam mutfak dolaplarıyla dekorasyona estetik ve havadar bir işlev katılabilmektedir. Mutfak dolaplarına cam kapaklar eklemenin pek çok yararı vardır. Bunlardan ilki şeffaflıktır, cam sayesinde kapakları açmadan dolapta ne olduğu görülebilmektedir. Tamamen şeffaf, yarı saydam, desenli, şeritli veya siyah cam gibi pek çok model seçeneği vardır. Üstelik farklı dekorasyon stillerine uygun olarak hemen hemen her tarza uygun bir cam kapak bulunabilmektedir. Kapak konstrüksiyonlarında kullanılan bazı cam kapak modelleri aşağıda gösterilmektedir (Şekil 15) (URL 5, 2018).

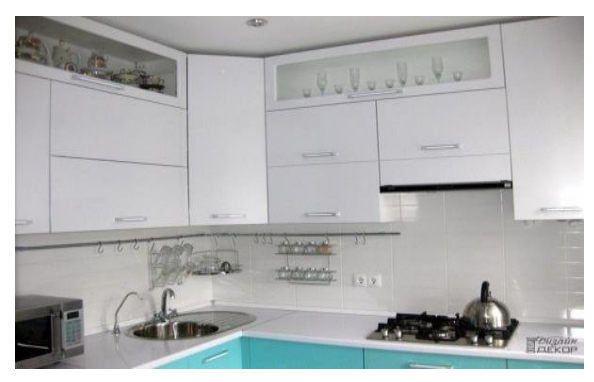

a- Şeffaf Cam

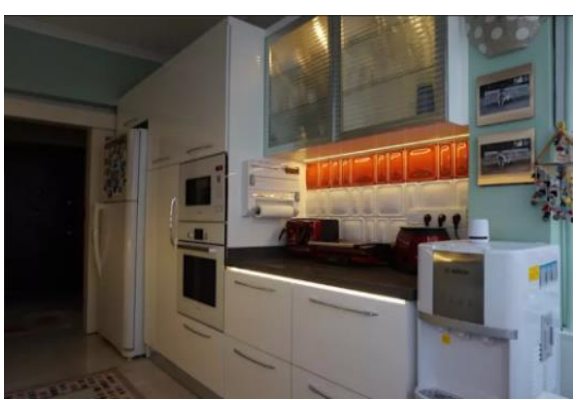

c- Şeritli Cam

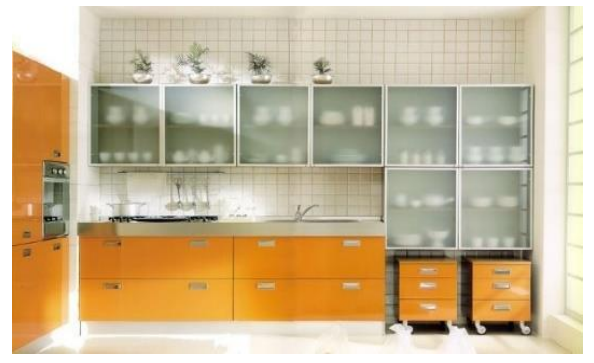

b- Buzlu Cam

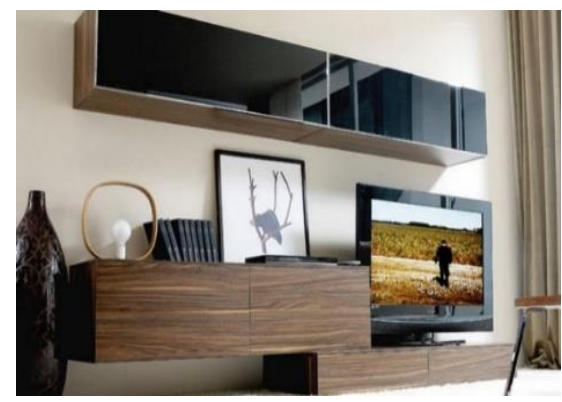

d- Siyah Cam Kapak

Şekil 15. Cam kapak modellerine ait örnekler. 


\subsection{Kapak sistemlerinde maliyet karşılaştırması}

Bilindiği gibi birim maliyet karşılaştırılmalarında ürünün özelliğine göre farklı kriterler esas alınmaktadır. Mutfak mobilyası imalatında maliyetlerin hesaplanmasında $\mathrm{m}^{2}$ veya mtül birimlerinin esas alındığ görülmektedir (URL 7, 2019; Kurtoğlu ve Dilik, 2020). Araştırma kapsamında incelenen işletmenin uyguladığı mutfak projeleri üzerinden 2019 yılı için belirlenen kapak çeşitlerine göre $\mathrm{m}^{2}$ birim maliyetler Çizelge 1 'de gösterildiği gibi tespit edilmiştir.

Çizelge 1. Kapak çeşitlerine göre tespit edilen birim maliyetler (2019).

\begin{tabular}{|c|c|c|}
\hline Mutfak kapak çeşidi & Detay & Birim fiyatı $\left(\mathbf{M}^{\mathbf{2}}\right)$ \\
\hline Akrilik Kapak Mutfak $\left(\mathrm{m}^{2}\right)$ & Tezgâh hariç - Montaj dahil. & $750 \mathrm{TL}$ \\
\hline Membran Mutfak $\left(\mathrm{m}^{2}\right)$ & Tezgâh hariç - Montaj dahil. & $600 \mathrm{TL}$ \\
\hline Lake Kapak Mutfak $\left(\mathrm{m}^{2}\right)$ & Tezgâh hariç - Montaj dahil. & $750 \mathrm{TL}$ \\
\hline Metal Kapak Mutfak $\left(\mathrm{m}^{2}\right)$ & Tezgâh hariç - Montaj dahil. & $850 \mathrm{TL}$ \\
\hline Siyah Cam Kapak Mutfak $\left(\mathrm{m}^{2}\right)$ & Tezgâh hariç - Montaj dahil. & $700 \mathrm{TL}$ \\
\hline Laminat Kapak Mutfak $\left(\mathrm{m}^{2}\right)$ & Tezgâh hariç - Montaj dahil. & $650 \mathrm{TL}$ \\
\hline Masif Kapak Mutfak $\left(\mathrm{m}^{2}\right)$ & Tezgâh hariç - Montaj dahil. & $950 \mathrm{TL}$ \\
\hline
\end{tabular}

Buradan birim maliyeti en yüksek olan kapakların masif kapak mutfaklarda, en düşük birim maliyete sahip olanların ise membran ve laminat kapak mutfakların olduğu görülmektedir. Araştırma kapsamında metretül üzerinden belirlenen birim maliyetlerin ise; aşağıdaki gibi tespit edilmiş olup, bunlarında $\mathrm{m}^{2}$ birim maliyetlerine paralellik gösterdiği ortaya çıkmıştır.

- Akrilik Mutfak Dolabı - Gövde MDF- Çizilmez Akrilik - Metretül Fiyatı 900 TL

- Membran Mutfak Dolabı - Gövde MDF- Metretül Fiyatı 800 TL

- Lake Mutfak Dolabı - Gövde Lake MDF- Metretül Fiyat1 1.500 TL

- Siyah Cam Kapak Mutfak Dolab1 - Gövde MDF- Metretül Fiyatı 800 TL

- Masif Mobilya Mutfak Dolab1 - Gövde MDF- Metretül Fiyatı 1.650 TL

- Alüminyum Çerçeve Kapaklı Mutfak Dolabı- Gövde MDF- Metretül Fiyatı 850 TL

- Laminat Mutfak Dolabı - Gövde MDF- Metretül Fiyatı 600 TL

\section{Sonuçlar ve Öneriler}

Araştırma kapsamında mobilya endüstrisindeki kapak konstrüksiyonlarının gelişim ile ilgili inceleme ve tespitler çerçevesinde aşağıdaki sonuçlara ulaşılmıştır.

- Kapak konstrüksiyonlarının çeşidinin kapağın hareket biçiminin belirlediği ortaya çıkmaktadır. Kapakların mobilyanın hareket yönlerinin ve biçimlerinin belirlenmesini de sağladığı, bu amaçla, günümüzde daha çok bindirme çıtalı ve lambalı kapaklardan ziyade, bağımsız açılan kapakların uygulandığı görülmektedir.

- Bağımsız açılan kapakların, özellikle çok kapaklı mutfak dolapları ile kitaplık ve vitrin kapaklarında kullanılmakta olduğu ve bu tür kapaklara kilit takılmayıp yaylı, plastik makaralı veya mıknatıslı çıtçıtlarla kapalı durmalarının sağlanmakta olduğu belirlenmiştir.

- Kapak çeşidinin her ne kadar müşterinin isteğine ve teknolojik şartlara bağlı olarak değiştiği görülse de kapak konstrüksiyonlarında kullanım alanının önemli faktör olarak 
karşımıza çıktığı görülmektedir. Örneğin, dar alanlar için katlanır veya sürme kapak kullanım zorunluluğu gibi.

- Gerek üretici gerekse tüketici tercihinde etkili faktörlerin başında gelen mobilya üretim maliyetlerinde kapak konstrüksiyonlarının önemli bir payının olduğu ortaya çıkmıştır. Trendlerin etkisi gözetilerek mutfak mobilyasında en çok tercih edilen kapak çeşitlerinin birim maliyet sıralamasının en fazladan en aza doğru; lake kapaklar, akrilik kapaklar, membran kapaklar, metal çerçeve kapaklar, cam kapaklar ve laminat kapaklar şeklinde olduğu ortaya çıkmıştır.

- Böylece, son yıllardaki mobilya tasarımlarında, işletmelerin sadece kapak konstrüksiyonlarındaki değişiklikler ile mobilya pazarında yer almaya çalıştıkları gerçeğinden hareketle, gelişim süreci içerisindeki mobilya sektörümüzde kapak konstrüksiyonlarının ön planda tutulmasının gerekliliği ortaya çıkmıştır. Bu kapsamda, mobilya sektörünün gerek uluslararası rekabet gerekse model geliştirilmesindeki etkinliği açısından işletmelerin, kapak konstrüksiyonlarına yönelik Ar-Ge ve Ür-Ge çalışmalarına öncelik ve önem vermelerinin gerekli olduğu önerisi ileri sürülmüştür.

\section{Teşekkür}

Bu çalışma, 02-05 Kasım 2020 tarihinde düzenlenmiş olan "VI. International Furniture Congress-IFC 2020 KTÜ, Trabzon/Turkey” kongresinde sözlü olarak sunulmuştur. Kullanıcı tercihleri ve uygulama maliyetlerinin belirlenmesindeki katkılarından dolayı "Dağlı Mobilya ve Dekorasyon İşletmesine" teşekkürlerimizi sunarız.

\section{Kaynaklar}

Dilik, T., (2019), İç mekân dekorasyon teknikleri ders notu, İ.Ü.-Cerrahpaşa Orman Fakültesi, Orman Endüstri Mühendisliği Bölümü, Bahçeköy/İstanbul.

Dilik, T., Uçar, E., (2017), A research on the preferences of material and size in the Turkish kitchen furniture industry. Journal of the Faculty of Forestry Istanbul University 67(2), 116-122. DOI: 10.17099/jffiu.292737.

Kurtoğlu, A., Dilik, T., (2019), Mobilya ve doğrama konstrüksiyonları ders notu (Basılmamıştır), İ.Ü.-Cerrahpaşa Orman Fakültesi, Orman Endüstri Mühendisliği Bölümü, Bahçeköy/İstanbul.

Kurtoğlu, A., Dilik, T., (2020), Mobilya endüstrisi ders notu (Basılmamıştır), İ.Ü.-Cerrahpaşa Orman Fakültesi, Orman Endüstri Mühendisliği Bölümü, Bahçeköy/İstanbul.

Kurtoğlu, A., (2000), Ağaç malzeme yüzey işlemleri 1. Cilt: Genel Bilgiler, İ.Ü. Orman Fakültesi, Orman Endüstri Mühendisliği Bölümü, Üniversite Yayın No:4262, Fakülte Yayın No: 463, ISBN 975-404-590-9 (1.Cilt), İstanbul, 2000.

Muğla, K., (2010), Farklı yüzey kaplama malzemelerinin MDF levhaların yüzey özellikleri üzerine etkileri, Bartın Üniversitesi, Fen Bilimleri Enstitüsü, Bartın.

URL 1, (2011), Mobilya ve iç mekân tasarımı-kapak hazırlama, T.C. Millî Eğitim Bakanlığı, Ankara, http://megep.meb.gov.tr/mte_program_modul/moduller_pdf/Kapak (Son Erişim Tarihi: 05/10/2019).

URL 2, (2019), Mutfak dolapları alırken tüketicilerin dikkat etmesi gereken hususlar ayrınt1lar, https://www.manset61.com/ekonomi/mutfak-dolaplari-alirken-tuketicilerindikkat-etmesi-gereken-hususlar-h1213.html, (Son Erişim Tarihi: 16/12/2019).

URL 3, (2018), Zeren lake boya sistemleri, http://www.lakeboya.com/uygulama/lake-boyanasil-yapilir/ (Son Erişim Tarihi: 26/11/2018). 
URL 4, (2018), Gilan Metal, Alüminyum Kapak Kulp Ve Bağlantı Modelleri http://gilanmetal.com/portfolio-items/prf-03-ve-prf-05-aluminyum-cerceve-kapak-icink02-model-kulp/?portfolioID=356 (Son Erişim Tarihi: 07/12/2018).

URL 5, (2018), Homify, cam kapaklar ile ilgili genel bilgiler, https://www.homify.com.tr/yeni_fikirler/6076975/13-fotografla-cam-kapakli-mutfakdolaplari-ve-uyumlu-oldugu-stiller (Son Erişim Tarihi: 30/12/2018).

URL 6, (2018), Doorka, membran kapak kullanım alanları ve tanımı, http://doorka.com.tr/membran-kapak-nedir.html (Son Erişim Tarihi: 16/12/2019).

URL 7, (2019), Mutfak dolaplar1 modelleri ve fiyatları, https://www.fezamutfak.com/2019mutfak-dolaplari-modelleri-ve-fiyatlari (Son Erişim Tarihi: 16/12/2019). 